\title{
Use of Inoculum, Water and Percolate as Strategy to Avoid Inhibition on Dry-Batch Anaerobic Digestion of Organic Fraction of Municipal Solid Waste
}

\author{
Ildefonso Rocamora ${ }^{1}$ - Stuart T. Wagland ${ }^{1} \cdot$ Raffaella Villa $^{1,2} \cdot$ Edmon W. Simpson $^{3} \cdot$ Oliver Fernández $^{3}$. \\ Yadira Bajón-Fernández ${ }^{1}$
}

Received: 2 March 2021 / Accepted: 22 June 2021 / Published online: 12 July 2021

(c) The Author(s) 2021

\begin{abstract}
The impact of inoculum to substrate ratio (I:S) and the addition of water and percolate on stopping inhibition in dry batch anaerobic digestion of organic fraction municipal solid waste (OFMSW) was investigated. In particular, ratios of I:S from 1:2 to $1: 16$ and total solid contents from 40 to $25 \%$ with water and percolate addition were analysed. Tested I:S did not avoid acidification of the anaerobic digesters (ADs), and the highest biogas and methane production (16.2 and $1.7 \mathrm{~L} / \mathrm{kg} \mathrm{VS}$ added, respectively) was achieved with the 1:4 ratio. Water addition was also insufficient to avoid acidification, and while biogas increased as TS decreased, $40.9 \mathrm{~L} / \mathrm{kg} \mathrm{VS}_{\text {added }}$ for $25 \% \mathrm{TS}$, methane yield remained low at $1.2 \mathrm{~L} / \mathrm{kg} \mathrm{VS}$ added due to the inhibition of methanogenic archaea. Percolate addition proved a suitable strategy to increase $\mathrm{pH}$ buffering, with an increased methane production of $199.4 \mathrm{~L} / \mathrm{kg} \mathrm{VS}_{\text {added }}$ at similar TS ranges (27\%). Impact on kinetics of methane formation was assessed by kinetic modelling with logistic model identified as the better fit for most of the ADs. Shorter lag phases were observed as TS were reduced, regardless of the acidification, as mass transfer limitations were reduced at the beginning of the batch, but an increase was observed when percolate was used instead of water. Increases of the maximum methane rate $\left(R_{\max }\right)$ was also achieved with TS reduction, but only when acidification was avoided. This study has highlighted the need to profile percolate composition during batch digestion in order to balance recirculation of nutrients, microbial communities and toxic compounds.
\end{abstract}

\section{Graphic Abstract}

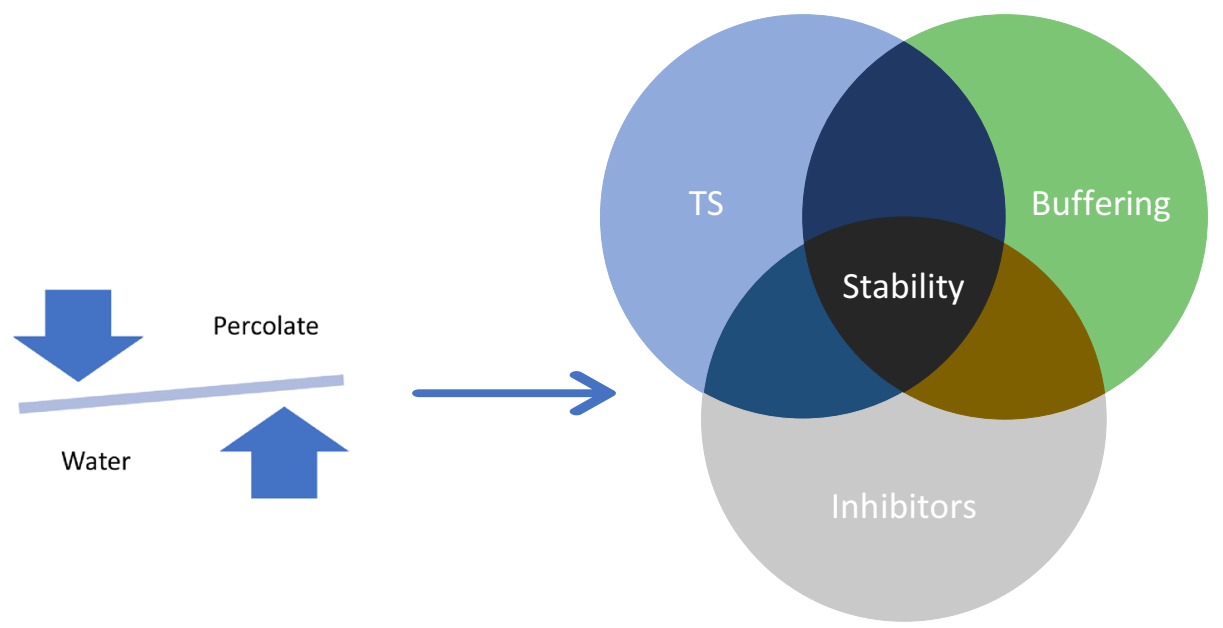

Keywords Acidification $\cdot$ Inhibition $\cdot$ Buffering effect $\cdot$ Kinetic modelling

Extended author information available on the last page of the article 


\section{Statement of Novelty}

The novelty of this manuscript lies in the clarification of contradicting information available in literature about strategies to avoid inhibition in dry batch anaerobic digestion of the organic fraction of municipal solid waste (OFMSW). This manuscript evidences that common industrial practices like increasing inoculum amounts or moderate dilutions with water allow for increased process stability and onset of biogas production, respectively, but do not suffice to guarantee a stable process. Percolate addition was the only tested strategy able to prevent acidification, demonstrating that balancing percolate composition in terms of nutrients, microbial communities and inhibitors is critical to sustain biogas yields. The work advances understanding of dry digestion, informing optimisation strategies and with potential to impact its uptake as a OFMSW treatment option.

\section{Introduction}

Dry Anaerobic Digestion (AD) is proven to be an appropriate technology to treat high solid organic wastes [1], producing biogas rich in methane that can be used as a renewable energy source and a digestate that can be used as fertilizer. Around 27 million tons of organic fraction of municipal solid waste (OFMSW) ended up in landfill in Europe in 2018 $[2,3]$ with a forecast of 209 million tons in the next 15 years in Europe alone [2], which constitutes a threat for sustainable waste management and poses a risk for uncontrolled greenhouse gas emissions [4]. The target by governments across Europe to reduce waste disposal to landfill [5] makes of the OFMSW an ideal feedstock for this type of processes.

Currently, batch operated reactors are the most common dry $\mathrm{AD}$ processes due to their simpler operation compared to continuous systems and the similarity to in-vessel composting processes [6-8]. In this process fresh material is usually inoculated with material digested from a previous batch, as a method to provide the necessary microbial population to the new substrate [7, 9], and usually loaded into the digesters using a front-end loader, similarly to the composting processes. To compensate for the lack of mixing, the percolate collected from the reactor or water can be recirculated to the mixture, improving homogenisation of the system.

When compared to wet $\mathrm{AD}$, reports show longer digestion times, lag phases and lower methane productions by $\mathrm{kg}$ of volatile solid (VS) treated $[6,7,10,11]$. These potential obstacles have been related to the amount of "free water" in the system. Free or available water can act as solvent for soluble compounds, this availability decreases when TS increase [12] in turn affecting the transport of soluble content within the reactor [13] but also the metabolic processes of the microbial communities [14]. Abbassi-Guendouz et al. [15] reported a reduction of the microbiological hydrolysis rate as TS were increased from 10 to $25 \%$ due to reduced diffusion of substrate, and a physical limitation to liquid and gas mass transfer when TS were over $30 \%$. In their study the faster biogas formation kinetics and methane yields obtained at the lowest TS content of $10 \%$ declined when TS was increased [15]. Other authors [16, 17] reported a linear response between methane production rate and water content in the feedstock. Furthermore, although widely used, the performance of dry ADs treating OFMSW is still frequently hindered by accumulation of inhibitors such as volatile fatty acids (VFA) and free ammonia (FA) [18]. In addition to solid content, different hypotheses have been posited in literature about the inhibitory mechanisms in dry AD. Some authors $[19,20]$ suggested that methanogens inhibition at high solids contents was explained by the slow diffusion of dissolved inhibitory products like VFA and FA inside the organic matrix, generating local accumulation and inhibition at microbial scale. Abbassi-Guendouz et al. [15] points in a different direction, suggesting that methanogenesis inhibition was mainly caused by a limited gas transfer resulting in local accumulation of gases that lead to VFA accumulation [15]. These different theories highlight the lack of knowledge in the specific mechanisms intervening in inhibitory accumulation at high TS contents, which is paramount to avoid inhibition and optimise the dry batch $\mathrm{AD}$ process.

Two process parameters have provided promising results for limiting inhibition in high solids digestion: inoculum to substrate ratio (I:S) and moisture content of the digester [21, 22]. An increase in inoculum at the beginning of the batch process is also one of the most common solutions in industry to avoid instability in dry batch AD [7], although this will reduce the capacity of the plant to treat new waste. A higher I:S ratio increases the amount of anaerobic microbial communities, including that of methanogens, and improves their contact with the organic substrate, thus avoiding VFA accumulation, accelerating kinetics [23] and improving the overall community resistance to peaks of inhibitors [9,24].

On this note Neves et al. [41] reported a pH drop from 7 to 5.5 when digesting kitchen waste at lab scale following a reduction of the I:S from 2:1 to 1:2, with a parallel tenfold decrease in methane production due to system acidification. Different values are reported in literature as optimum I:S ratios for dry batch AD of OFMSW, with some studies suggesting optimum ratios from 1:1.5 to 1:2.5 [24], while others report drops on methane production if the inoculum content is reduced beyond a I:S ratio of 1:4 for OFMSW [25]. Lack of knowledge around the appropriate ratios is still present, as they are very dependent on the type of feedstock and the digester's operational conditions, and more research is necessary to optimise ratios to avoid inhibition and boost kinetics and production when using OFMSW as a substrate. 
Control of moisture strategy is usually accomplished via recirculation of water or liquid percolate produced during the process, with immersion being also used [26-28], as a mixing mechanism within the reactors [6]. Water has been successfully used in several studies to reduce TS, improving methane yields and kinetics. Fernández et al. [45] reported a $17 \%$ increase in methane production and a decrease on the start-up period from 28 to 14 days as TS were reduced from 30 to $20 \%$ when digesting OFMSW in dry batch AD conditions. Further to this, Forster-Carneiro et al. [43] reported a $36 \%$ increase after 60 days of lab-scale batch digestion of food waste and double cumulative methane after 5 days of operation when TS were reduced from 30 to $25 \%$. However, the use of clean water is seen as an environmental and economic problem due to the high volumes, the risk of contamination linked to leaks and the need for treatment. To avoid this, the reactor's percolate provides a good sustainable solution, as is generated during the dry digestion process, and has the advantages of being inexpensive and available [29]. Authors like Liao et al. [30] reported that the use of percolate has additional advantages to providing moisture, helping to regulate $\mathrm{pH}$ due to the buffering capacity of FA and its conjugated base. This buffering capacity maintains the biochemical balance between the acidogenic and methanogenic microorganisms, avoiding the inhibition in the ADs. In addition, Wilson et al. [31] reported a reduction in the solid inoculum required, from 50 to $10 \%$, during the start-up of leachate bed batch dry ADs. The percolate addition from previously digested OFMSW helped maintaining stability and improved methane yields. Although percolate is commonly used in industrial sites with positive performances, Sponza and Ağdağ [32] reported negative effects when recirculation is excessive while digesting municipal solid waste in a lab-scale digester. Results showed a 23\% drop in methane production, together with a drop in $\mathrm{pH}$ and an increase in VFA when daily percolate recirculation was increased from 13 to $30 \%$ of the reactor volume.

In relation to this, it is also important to understand the role of the I:S ratio and moisture content as strategies to avoid inhibition in the ADs while digesting the OFMSW in batch conditions. The present study aimed at understanding the impact of (1) solid inoculum to substrate ratio (I:S), (2) water and (3) percolate addition on process performance and mitigation of inhibition in dry batch $\mathrm{AD}$. Also, mathematical modelling is presented as a tool to analyse the impact on kinetics of methane formation, with inhibition quantified as both lag phase and reduced production rates.

\section{Materials and Methods}

\section{Feedstock, Inoculum and Percolate}

The substrate $(\mathrm{S})$, percolate $(\mathrm{P})$ and solid inoculum (I) used were obtained from a dry batch $\mathrm{AD}$ facility operating at mesophilic conditions in Buckinghamshire treating 32,000 tons of OFMSW per year and operated with a I:S ratio of 1:2 in VS. The substrate (OFMSW) was the recovered organic fraction from waste not segregated at source and mechanically treated to remove recyclables and inert materials. Particulate size was smaller than $50 \mathrm{~mm}$. Solid inoculum was sampled when an exchange of digester took place at the full-scale plant after a 28-day digestion period. Percolate was accessible at any moment from the percolate tank, which is a mixture coming from the different batch ADs at different stages of the digestion. All samples were collected form the digester, the waste coming into the facility and the percolate tank at the same time in containers and kept at $4{ }^{\circ} \mathrm{C}$ for less than a week while preliminary analysis was performed. Characteristics of I, P and S for each experiment are shown in Table 1.

\section{Batch ADs Configuration}

Each AD consisted of $2.6 \mathrm{~L}$ containers with $26 \mathrm{~cm}$ in length, $19 \mathrm{~cm}$ width and $8.5 \mathrm{~cm}$ height to mimic a garage-type digester without recirculation. The reactors were equipped with a fitting at the top to release the biogas, which was stored in gas bags and measured every two days. The reactors were maintained at mesophilic conditions $\left(38^{\circ} \mathrm{C}\right)$ in a Binder FP720 incubator (Binder GmbH, Tuttlingen, Germany). For all the experiments $0.5 \mathrm{~kg}$ of different mixtures of S and I were loaded as feed. All conditions were set in triplicates and digestion carried until the daily increase in methane production was lower than $1 \%$ the cumulative volume for 3 consecutive days [33]. All gas volumes reported were corrected to standard temperature $(273 \mathrm{~K})$ and pressure (1 atm) (STP).

Table 1 Inoculum, substrate and percolate characterisation

\begin{tabular}{llrlll}
\hline Experiment & & \multicolumn{1}{l}{ TS $(\%)$} & VS $(\%)$ & VS/TS (\%) & $\mathrm{pH}$ \\
\hline 1 & $\mathrm{~S}$ & $40.5 \pm 7.3$ & $26.8 \pm 3.5$ & $67.7 \pm 14.8$ & $5.3 \pm 0.2$ \\
& $\mathrm{I}$ & $51.4 \pm 3.6$ & $17.5 \pm 1.8$ & $34.2 \pm 4.3$ & $8.9 \pm 0.1$ \\
2 & $\mathrm{~S}$ & $38.8 \pm 4.3$ & $29.8 \pm 5.3$ & $76.6 \pm 5.0$ & $5.4 \pm 0.3$ \\
& $\mathrm{I}$ & $42.7 \pm 0.6$ & $19.4 \pm 2.6$ & $45.7 \pm 6.3$ & $8.2 \pm 0.1$ \\
3 & $\mathrm{~S}$ & $50.7 \pm 1.8$ & $30.6 \pm 1.1$ & $60.4 \pm 4.4$ & $5.2 \pm 0.3$ \\
& $\mathrm{I}$ & $35.7 \pm 4.0$ & $16.1 \pm 2.1$ & $45.7 \pm 8.8$ & $8.6 \pm 0.1$ \\
& $\mathrm{P}$ & $3.7 \pm 0.1$ & $1.6 \pm 0.1$ & $43.5 \pm 0.3$ & $8.1 \pm 0.1$ \\
\hline
\end{tabular}


The impact of the I:S content on the process was investigated by operating $\mathrm{ADs}$ at I:S ratios of 1:2, 1:4, 1:8 and $1: 16$ in VS, which were chosen as ratios that would reduce inoculum use and allow higher feedstock treatment capacity than in the full-scale plant, currently operating with a $1: 2$ ratio. The first experiments to understand the impact of water addition were operated with a I:S of 1:4, identified in the I:S test as yielding the best performance, and different amounts of water were added only at the beginning to reduce TS to values of $25,30,35$ and $40 \%$. To analyse the percolate effect on the process all sets of triplicates were loaded with the same I:S ratio previously used (1:4), but different amounts of percolate were added instead of water at the start of the digestion, reducing the TS content to $27,30,33$ and $36 \%$ in the digesters. Blanks were used for each TS content in both experiments, with percolate or water solely added at the beginning of the batch digestion process as a way to test the effect of different TS content and the influence of percolate composition in contrast with water.

\section{Analytical Methods}

TS and VS content were determined by standard methods [34], pH of the solid fraction was measured with a laboratory pH meter HI-991003 (HANNA instruments Ltd., Leighton Buzzard, UK) generally used for soils, while the liquid fraction was measured with a HQ440D Hatch multi-meter (HACH LANGE LTD, Manchester, UK). The liquid fraction's total alkalinity was obtained by titration [35].

The liquid fraction was also analysed for total ammonia nitrogen (TAN) and VFA content. Before performing the analysis, the samples were centrifuged in a Megafuge 16R centrifuge (Thermo Scientific, Massachusetts, USA) for $20 \mathrm{~min}$ at $4696 \mathrm{~g}$ and $19{ }^{\circ} \mathrm{C}$, then the supernatant was centrifuged again for 40 more minutes. Before TAN analysis the supernatant from the centrifugation step was filtered with a $0.45 \mu \mathrm{m}$ syringe filter (Whatman, Kent, UK). For the VFA's analysis a $0.2 \mu \mathrm{m}$ syringe filter (Sartorius AG, Goettingen, Germany) was used. Total ammonia nitrogen (TAN) was determined using cell test kits and a NOVA 60 Spectroquan photometer (Merck KGaA, Darmstadt, Germany). Free ammonia $\left(\mathrm{NH}_{3}\right)$ was calculated with total ammonia and $\mathrm{pH}$ using Eq. (1) [36]:

$N H_{3}=\operatorname{TAN}\left(1+\frac{10^{-p H}}{10^{-0.09018+\frac{279.92}{T(k)}}}\right)$

The VFA content was determined by high performance liquid chromatography (HPLC) in a Shimadzu VP Series unit (Milton Keynes, UK), using similar methodology to Bajón Fernández et al. [37] but adapting run time to $90 \mathrm{~min}$. Total VFA concentration (TVFA) (acetic, propionic, iso-butyric, n-butyric, iso-valeric and n-valeric) was expressed as grams of acetic acid equivalent per litre ( $\mathrm{g}$ Ac-eq/L).

The biogas produced in the different ADs was stored in gas bags, and the total volume measured every two days by water displacement. The methane $\left(\mathrm{CH}_{4}\right)$ percentage in the biogas was obtained with an infrared analyser Servomex 1440D (Servomex, Crowborough, UK).

\section{Modelling Kinetics of Methane Formation}

Methane production in all the experiments was modelled using the average of the triplicates obtained in each experiment, where both lag phase increases, and production rates reduction were used to analyse the extent of inhibition on methane formation kinetics. Five models widely used in literature were used to estimate yield and kinetic parameters, with the goal of finding the best fit for the methane production of the process. The models were first order kinetics (FO), Eq. (2), two stage model (2S), Eq. (3), modified Gompertz equation (GM), Eq. (4), logistic function (LM), Eq. (5), and transference function (TF), Eq. (6) [38, 39].

$$
\begin{aligned}
& C=C_{\text {max }} \times[1-\exp (-k \times t)] \\
& C=C_{1} \times\left[1-\exp \left(-k_{1} \times t\right)\right]+C_{2} \times\left[1-\exp \left(-k_{2} \times t\right)\right] \\
& C=P \times \exp \left[-\exp \left(\frac{R_{\max } \times e}{P} \times(\lambda-t)+1\right)\right] \\
& C=\frac{R_{\max }}{1+\exp \left[\frac{4 \times R_{\max } \times(\lambda-t)}{P}+2\right]} \\
& C=P \times\left[1-\exp \left(-\frac{R_{\max } \times(t-\lambda)}{P}\right)\right]
\end{aligned}
$$

where $t$ is the time (d), $C$ is the cumulative methane yield at a certain time $t\left(\mathrm{~L} \mathrm{CH}_{4} / \mathrm{kg} \mathrm{VS}\right.$ added $), \mathrm{C}_{1}$ and $\mathrm{C}_{2}$ are cumulative methane yields for the first and second stages, $C_{\max }$ is the maximum methane yield ( $\mathrm{L} \mathrm{CH}_{4} / \mathrm{kg} \mathrm{VS}$ added $), R_{\text {max }}$ is the maximum methane rate $\left(\mathrm{L} \mathrm{CH}_{4} / \mathrm{kg} \mathrm{VS} \mathrm{Vdded}_{\text {ad }} / \mathrm{d}\right), \lambda$ is the lag phase (d), $\mathrm{P}$ is the methane yield potential $\left(\mathrm{L} \mathrm{CH}_{4} / \mathrm{kg}\right.$ $\left.\mathrm{VS}_{\text {added }}\right)$ and $k, k_{1}$ and $k_{2}$ are rate constants $\left(\mathrm{d}^{-1}\right)$.

All parameters were calculated by non-linear regression using Solver in Microsoft excel, with the residual sum of squares (RSS), Eq. (7), as set objective. Both RSS and R-square, Eq. (8), were used as indicative values of quality of the model fit [40].

$$
R S S=\sum_{j}^{m}\left(X_{j}-Y_{j}\right)^{2}
$$


$R^{2}=\left[\frac{m\left(\sum_{j}^{m} X_{j} Y_{j}\right)-\left(\sum_{j}^{m} X_{j}\right)\left(\sum_{j}^{m} Y_{j}\right)}{\sqrt{\left[m \sum_{j=1}^{m} X_{j}^{2}-\left(\sum_{j=1}^{m} X_{j}\right)^{2}\right]\left[m \sum_{j=1}^{m} Y_{j}^{2}-\left(\sum_{j=1}^{m} Y_{j}\right)^{2}\right]}}\right]^{2}$

where $Y_{j}$ is the measured value and $X_{j}$ the predicted value by the model. An RSS value of 0 shows a perfect correlation between the model and the measured data. For $\mathrm{R}^{2}$ a value of 1 shows a perfect fitting, while a value of 0 implies no correlation.

\section{Results and Discussion}

\section{Role of Inoculum to Substrate Ratio on Controlling Process Inhibition}

The highest biogas and methane yields were observed for ratios 1:2 and 1:4 (Fig. 1a), with a lower performance for the other ratios tested. This was consistent with values reported in literature, where the total biogas yield dropped for ratios smaller than 1:4 when food waste was used as a feedstock
Fig. 1 a Biogas yield, methane yield per total VS added and final $\mathrm{pH}$ for different I:S. b Biogas yield, methane yield and final $\mathrm{pH}$ for different TS contents in ADs operated with an I:S ratio of 1:4 and water addition. c Biogas yield, methane yield and final $\mathrm{pH}$ for different TS contents in ADs operated with initial percolate addition and I:S ratio of 1:4. Production from blank reactors has not been subtracted

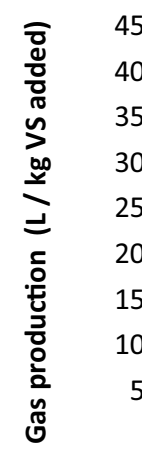

(a)

10

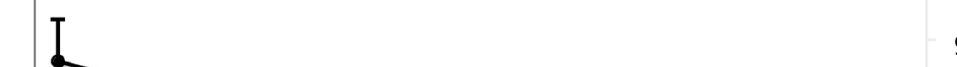

8

7 I

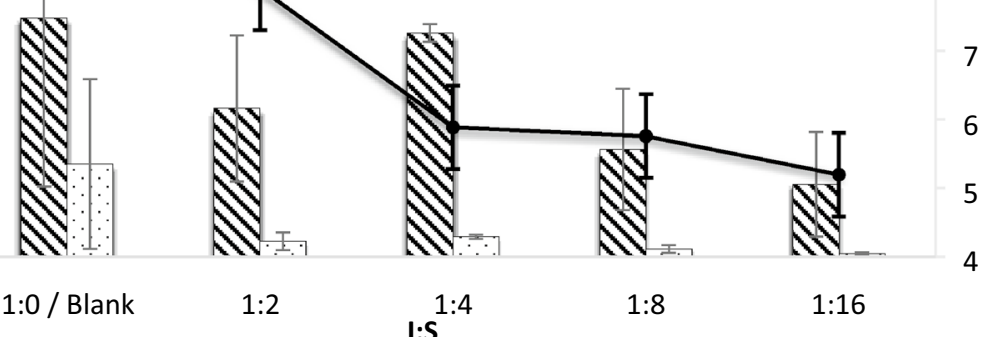

1:0 / Blank

I:S

$1: 16$

(b)

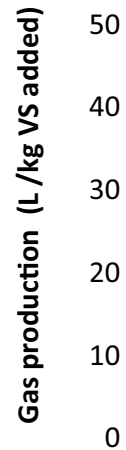

9

8 I

6

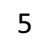

4

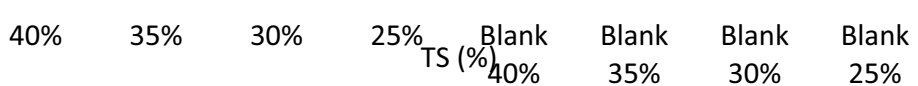

(c)

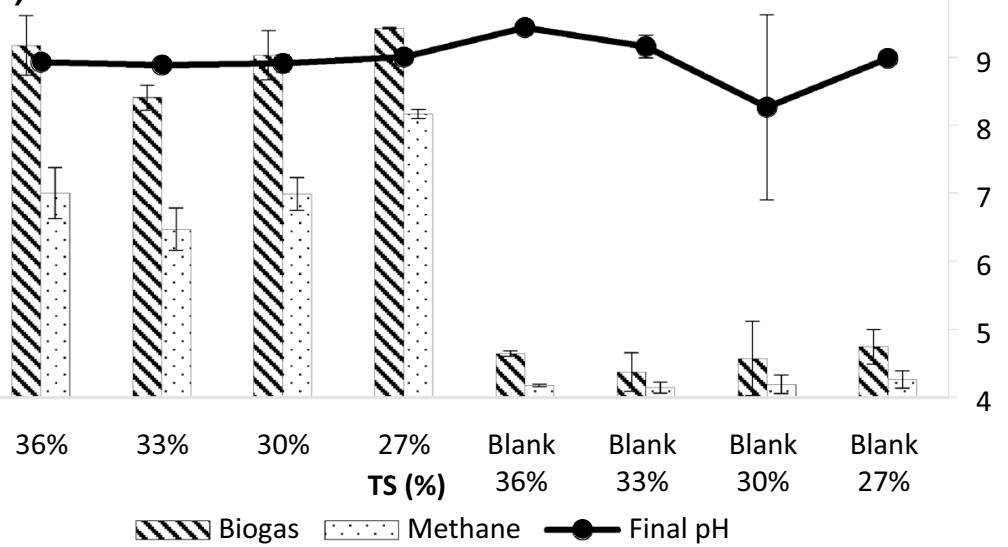


[25]. Inoculum ratios below 1:4 failed to avoid process inhibition, likely due to the lower concentrations of methanogenic archaea at the start of the batch process being insufficient to assimilate hydrolysis products at the required rate to avoid system acidification, agreeing with reports of several authors [41-43]. A drop in $\mathrm{pH}$ at the end of the experiment was observed as the inoculum amount was reduced in the ADs (Fig. 1a), with values as low as 5.2 for I:S ratio of 1:16. This low final $\mathrm{pH}$ resulted from an accumulation of VFA from the acidogenic step and inhibition of the activity of methanogenic microorganisms [44]. Only the reactors with I:S ratios above 1:2 were able to supress acidification and maintain $\mathrm{pH}$ within the values of 7 and 8.2 usually reported as stable for anaerobic digestion [6]. The blank reactors had the highest $\mathrm{pH}$ at 8.9 , as expected because of the lack of substrate hydrolysis. In any case, stable digestion could not be achieved for the I:S ranges tested due to the acidification of the ADs at the lower ratios and the lack of contact between the digestate and the substrate at the 1:2 ratio. The highest biogas and methane yields were obtained for the blank ADs, where no feedstock was added to the reactors (I:S of 1:0) (Fig. 1a). Methane yield was $10.1 \mathrm{~L} / \mathrm{kg} \mathrm{VS}_{\text {added }}$, which was almost 5 times higher than the experiment with I:S of 1:4 $(p=0.009)$. The low methane content $(<11 \%)$ in the test ADs indicates a high amount of $\mathrm{CO}_{2}$ in the biogas. This $\mathrm{CO}_{2}$ is produced in the acetogenesis phase, and the higher than $25-50 \%$ usual range [6] indicates that acetogenic bacteria transformation of organic acids into acetate is faster than the capacity of acetoclastic methanogens to transform them, which agrees with the hypothesis of insufficient amount of methanogenic archaea, due to low inoculum amounts, producing an acidification of the system. These results indicate that the range of I:S tested does not suffice to avoid accumulation of VFA at the start up period of the batch, which produces inhibition of the methanogenic archaea.

\section{Role of Water Addition on Controlling Process Inhibition}

Results showed an increase of biogas yield with a higher water content (Fig. 1b), with a ca. $85 \%$ higher biogas yield at $25 \% \mathrm{TS}(40.9 \mathrm{~L} / \mathrm{kg} \mathrm{VS}$ added $)$ compared to $40 \%(22.2 \mathrm{~L} / \mathrm{kg}$ $\left.\mathrm{VS}_{\text {added }}\right)(\mathrm{p}=0.004)$. The increased biogas performance was not reflected in the methane yield, as the values of $1.3 \pm 0.9$, $1.9 \pm 0.5,1.0 \pm 0.4$ and $1.2 \pm 0.8 \mathrm{~L} / \mathrm{kg} \mathrm{VS}$ added recorded for TS of $40 \%, 35 \%, 30 \%$ and $25 \%$, respectively, were not statistically different $(p=0.42)$. These results only agree partially with previous experiments available in literature, where Forster-Carneiro et al. [21] and Fernández et al. [45] reduced the TS content from 30 to $20 \%$ obtaining increases for both biogas and methane, without signs of inhibition. An increase of the water content produces a better homogenisation in the ADs, reducing diffusion problems, increasing interaction between microorganisms and nutrients; and diluting potential inhibitors [21, 46].

Although there was an improvement on biogas yields compared to the ADs without water addition (Fig. 1a), stable digestion was not achieved. The low $(<6 \%)$ methane content on the biogas indicated inhibition of methanogenic communities, which was ratified by the better performance of blank reactors which produced between 5.9 to $11.1 \mathrm{~L} \mathrm{CH}_{4} /$ $\mathrm{kg} \mathrm{VS}_{\text {added }}$; up to 10 times higher than the test ADs (Fig. 1b). Similarly to the experiments with no water addition (Fig. 1a), inhibition was caused by the acidification derived from VFA accumulation. VFA concentration was measured in the ADs where percolate was recovered (Table 2a), with a TVFA concentration of $20.6 \pm 2.6$ and $17.7 \pm 1.9 \mathrm{~g} \mathrm{Ac}-\mathrm{eq} / \mathrm{L}$ for the ADs with TS of 30 and $35 \%$, which is well above the considered inhibitory value of $8 \mathrm{~g} \mathrm{Ac}$-eq/L $[6,47]$, while the corresponding blanks had a much lower concentration of $0.4 \mathrm{~g} \mathrm{Ac-eq} / \mathrm{L}$. Final pH values between 5.7 and 6.2 were recorded for test reactors with different moisture content, while $\mathrm{pH}$ of blank ADs remained within non-inhibitory ranges of 8.1-8.4. FA increased as water content decreased (Table 2a), although it was not regarded as inhibitory for methane yields as the values recorded were much lower than those of $800 \mathrm{mg} / \mathrm{l}$ reported as inhibitory in previous literature [48-50]. This was further evidenced when considering the blank digesters, as they had higher concentration of FA than the test ADs (Table 2a) but achieved a higher methane yield (Fig. 1b).

\section{Role of Percolate Addition on Controlling Process Inhibition}

Percolate addition was tested to analyse if performance benefits in ADs with greater moisture content is solely related with an improved contact between microorganisms and substrate or the composition of liquid could influence the biogas/methane yields. Percolate addition led to higher methane yields and concentrations than experiments with water addition (Fig. 1c). Values obtained were 200.2 \pm 25.0 , $164.6 \pm 20.8,199.4 \pm 16.2$ and $277.8 \pm 4.4 \mathrm{~L} \mathrm{CH}_{4} / \mathrm{kg}$ $\mathrm{VS}_{\text {added }}$, with associated methane percentages of $56.0 \pm 1.7$, $58.0 \pm 1.2,59.4 \pm 0.4$ and $76.7 \pm 1.3 \%$ for the experiments at $36,33,30$ and $27 \% \mathrm{TS}$, respectively. The different impact in methane yields evidenced the role of percolate on buffering the system, providing a total alkalinity of $23.6 \mathrm{~g} / \mathrm{l}$. The results also proved that process improvement by liquid addition cannot rely solely on free water acting as a connecting matrix, but requires liquid to regulate $\mathrm{pH}$, which cannot be done by water alone. Percolate addition was able to buffer $\mathrm{pH}$ to levels of 8.9-9.0 (Fig. 1c), avoiding inhibition of methanogenic archaea and allowing conversion of VFA into methane, even when TVFA concentrations ranged from $1.6 \pm 0.3$ to $7.0 \pm 1.4 \mathrm{~g} \mathrm{Ac-eq/L}$ (Table $2 \mathrm{~b}$ ), under the $8 \mathrm{~g}$ 
Table 2 Methane percentage and final percolate characteristics for the experiments with (a) different water additions (b) different percolate additions; and initial analysis of percolate

\begin{tabular}{|c|c|c|c|c|c|c|}
\hline $\mathrm{I}: \mathrm{S}$ & TS $(\%)$ & $\mathrm{CH}_{4}(\%)$ & TVFA (g Ac-eq/L) & Total Alkalinity $(\mathrm{g} / \mathrm{L})$ & TAN (g/L) & FA $(g / L)$ \\
\hline \multicolumn{7}{|c|}{ (a) Experiment with different water additions } \\
\hline \multirow[t]{4}{*}{$1: 4$ (test ADs) } & 40 & $5.8 \pm 1.0$ & - & - & - & - \\
\hline & 35 & $5.2 \pm 1.0$ & - & - & - & - \\
\hline & 30 & $2.5 \pm 0.8$ & $20.6 \pm 2.6$ & - & $1.6 \pm 0.2$ & $5.0 \pm 0.7 \times 10^{-3}$ \\
\hline & 25 & $2.5 \pm 1.7$ & $17.7 \pm 1.9$ & - & $1.4 \pm 0.0$ & $1.2 \pm 0.1 \times 10^{-3}$ \\
\hline \multirow[t]{4}{*}{ 1:0 (blanks) } & 40 & $24.5 \pm 12.5$ & - & - & - & - \\
\hline & 35 & $28.7 \pm 4.6$ & - & - & - & - \\
\hline & 30 & $25.0 \pm 4.2$ & $0.4 \pm 0.1$ & - & $2.0 \pm 0.1$ & $0.50 \pm 0.05$ \\
\hline & 25 & $34.1 \pm 5.6$ & $0.4 \pm 0.1$ & - & $1.4 \pm 0.2$ & $0.29 \pm 0.08$ \\
\hline \multicolumn{7}{|c|}{ (b) Experiment with different percolate additions } \\
\hline Percolate characteristics & 4 & - & $0.6 \pm 0.1$ & $30.9 \pm 0.7$ & $3.8 \pm 0.3$ & $0.58 \pm 0.01$ \\
\hline \multirow[t]{4}{*}{ 1:4 (test ADs) } & 36 & $58.0 \pm 1.7$ & $1.6 \pm 0.3$ & $22.2 \pm 5.7$ & $4.4 \pm 1.2$ & $2.4 \pm 0.8$ \\
\hline & 33 & $56.0 \pm 1.2$ & $7.0 \pm 1.4$ & $26.3 \pm 0.0$ & $10.4 \pm 0.6$ & $5.3 \pm 0.3$ \\
\hline & 30 & $59.4 \pm 0.4$ & $1.9 \pm 0.2$ & $26.6 \pm 2.0$ & $9.9 \pm 1.1$ & $5.2 \pm 0.7$ \\
\hline & 27 & $76.7 \pm 1.3$ & $2.6 \pm 0.7$ & $27.5 \pm 2.1$ & $9.4 \pm 2.4$ & $5.4 \pm 1.7$ \\
\hline \multirow[t]{4}{*}{ 1:0 (blanks) } & 36 & $27.0 \pm 2.3$ & - & - & - & - \\
\hline & 33 & $25.4 \pm 1.8$ & $0.2 \pm 0.2$ & - & $5.3 \pm 0.6$ & $3.5 \pm 0.2$ \\
\hline & 30 & $34.8 \pm 17.1$ & $0.3 \pm 0.1$ & - & $6.6 \pm 1.4$ & $1.3 \pm 5.4$ \\
\hline & 27 & $35.0 \pm 3.6$ & $0.6 \pm 0.1$ & - & $8.7 \pm 4.1$ & $4.9 \pm 1.1$ \\
\hline
\end{tabular}

Ac-eq/L considered as inhibitory [6, 51]. Benbelkacem et al. [52] previously observed AD failure when the OFMSW was digested with no percolate addition but obtained $181 \mathrm{~L} \mathrm{CH}_{4} /$ $\mathrm{kg} \mathrm{VS}$ added when the OFMSW was saturated with percolate at the beginning of the digestion.
The highest ultimate biogas and methane yields were

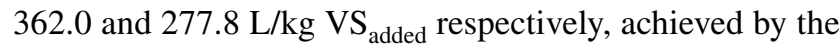
ADs with the highest amount of percolate added, at $27 \%$ TS. Kinetics for methane formation in this set of ADs was also the fastest and had the shortest lag phase (Fig. 2). To illustrate, methane yield after 28 days was $73 \%$ (190.9 L/

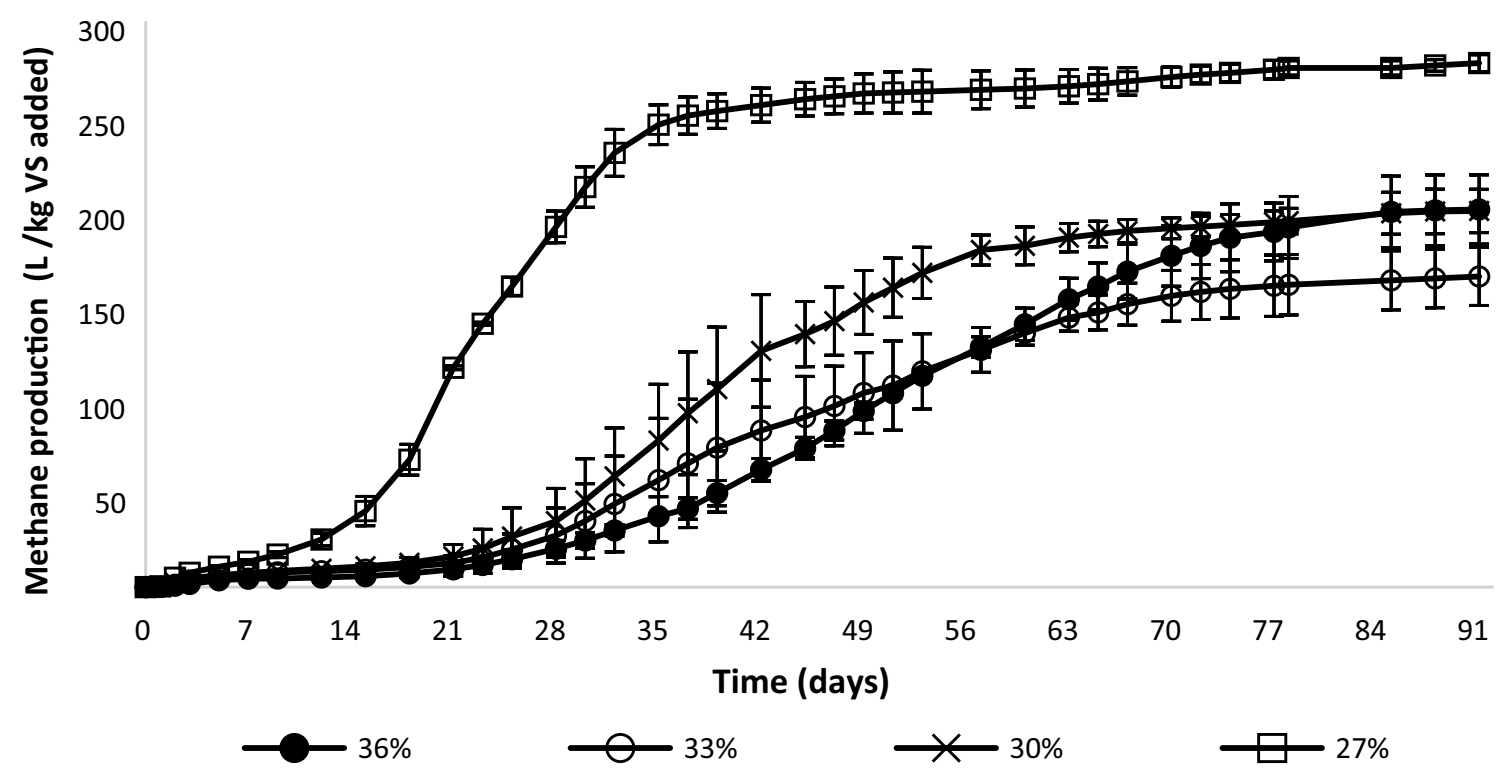

Fig. 2 Cumulative methane production for different percolate additions. Legend represent the total solids content (\%) within the reactors. Production from blank reactors has not been subtracted 
$\mathrm{kg} \mathrm{VS}_{\text {added }}$ ) of the ultimate methane yield at $27 \% \mathrm{TS}$, compared to $25 \%\left(20.3 \mathrm{~L} / \mathrm{kg} \mathrm{VS}_{\text {added }}\right)$ for the experiment at $36 \%$ TS $(p=0.03)$. This behaviour agrees with previous results. Some authors underlined the benefits of percolate addition on biogas formation kinetics. Dearman and Bentham [53], who reported an accelerated substrate degradation with methanogenesis starting $c a$. 20 days earlier in food waste dry ADs where total percolate added was doubled, even though no impact in ultimate yields was recorded. Further to this, Fdéz.-Güelfo et al. [54] recorded a reduction from 250 to 110 days on the start-up time when recirculating percolate in the digestion of OFMSW in a SEBAC system. Results provided earlier in this section evidence that percolate addition can prevent significant inhibition in batch dry digestion, but further investigation into the percolate composition and recirculation frequency that would enable process optimisation is paramount. Other authors, however, suggested that excessive percolate addition can negatively impact performance, either by accumulation of inhibitors $[9,32]$ or due to the collapsing of the feedstock matrix, reducing permeability [55]. For this reason, appropriate percolate recirculation regimes need to be designed considering the right balance between recirculated microorganisms, alkalinity, inhibitors and physical properties of the matrix. Further research into optimising methane yields is necessary considering dynamic percolate recirculation strategies as a function of its evolving biochemical composition, and strategies to alter percolate composition could be considered like VFA reduction in a secondary fixed methane digester [56].

\section{Impact of I:S, Water Addition and Percolate on Methane Formation Kinetics}

The experimental data obtained from the three different experiments was fitted into five different kinetics models in order to quantify the effect of the different conditions on process kinetics (Table 3). The models used can be divided into those which assume no delay in methane production (FO and 2S), and a second group (GM, LM, TF) where a lag phase is considered.

When different I:S ratios were tested on experiment 1 (Table 3), ratios of 1:2, 1:4 and 1:16 were better fitted to

Table 3 Parameters obtained after model fitting for the different experiments

\begin{tabular}{|c|c|c|c|c|c|c|c|c|c|c|c|c|c|}
\hline \multirow[t]{2}{*}{ Model } & & \multicolumn{4}{|c|}{$\begin{array}{l}\text { Experiment } 1 \\
\text { (different I:S) }\end{array}$} & \multicolumn{4}{|c|}{$\begin{array}{l}\text { Experiment } 2 \\
\text { (TS varied with water addition) }\end{array}$} & \multicolumn{4}{|c|}{$\begin{array}{l}\text { Experiment } 3 \\
\text { (TS varied with percolate addition) }\end{array}$} \\
\hline & & $1: 2$ & $1: 4$ & $1: 8$ & $1: 16$ & $40 \%$ & $35 \%$ & $30 \%$ & $25 \%$ & $36 \%$ & $33 \%$ & $30 \%$ & $27 \%$ \\
\hline \multirow[t]{4}{*}{1 st order } & $\mathrm{C}_{\text {Max }}$ & 1.8 & 2.3 & 1.5 & 0.3 & 1.5 & 2.1 & 1.0 & 1.2 & $1.0 \mathrm{E}+6$ & $6.3 E+04$ & $1.5 \mathrm{E}+03$ & $1.5 \mathrm{E}+3$ \\
\hline & $\mathrm{k}_{1}$ & 0.117 & 0.085 & 0.027 & 0.150 & 0.099 & 0.148 & 0.195 & 0.184 & $2.1 \mathrm{E}-6$ & $3.2 \mathrm{E}-5$ & $1.8 \mathrm{E}-3$ & $1.8 \mathrm{E}-3$ \\
\hline & RSS & 0.350 & 0.297 & 0.014 & 0.006 & 0.267 & 0.821 & 0.069 & 0.120 & $2.2 \mathrm{E}+4$ & $8.6 \mathrm{E}+3$ & $1.9 \mathrm{E} 4$ & $3.3 \mathrm{E}+4$ \\
\hline & $\mathrm{R}^{2}$ & 0.948 & 0.964 & 0.983 & 0.965 & 0.935 & 0.911 & 0.964 & 0.960 & 0.942 & 0.958 & 0.932 & 0.936 \\
\hline \multirow[t]{6}{*}{2 stages } & $\mathrm{C}_{1}$ & 0.0 & 0.6 & 0.1 & 0.3 & 0.0 & 0.5 & 1.0 & 1.2 & 0.0 & 0.0 & 0.0 & 0.0 \\
\hline & $\mathrm{C}_{2}$ & 1.8 & 1.7 & 80.9 & 0.0 & 1.5 & 1.5 & 0.0 & 0.0 & $1.2 \mathrm{E}+4$ & $1.0 \mathrm{E}+5$ & $1.2 \mathrm{E}+4$ & $3.2 \mathrm{E}+2$ \\
\hline & $\mathrm{k}_{1}$ & 0.0 & 0.085 & 0.269 & 0.15 & 0.000 & 0.148 & 0.195 & 0.184 & $5.5 \mathrm{E}-5$ & $5.5 \mathrm{E}-5$ & $5.5 \mathrm{E}-5$ & $5.5 \mathrm{E}-5$ \\
\hline & $\mathrm{k}_{2}$ & 0.117 & 0.085 & 0.0 & 0.02 & 0.099 & 0.148 & 0.000 & 0.016 & $1.8 \mathrm{E}-4$ & $1.9 \mathrm{E}-5$ & $2.1 \mathrm{E}-4$ & $2.8 \mathrm{E}-2$ \\
\hline & RSS & 0.35 & 0.297 & 0.01 & 0.006 & 0.267 & 0.821 & 0.069 & 0.120 & $2.2 \mathrm{E}+4$ & $8.6 \mathrm{E}+3$ & $1.9 \mathrm{E}+4$ & $3.3 \mathrm{E}+4$ \\
\hline & $\mathrm{R}^{2}$ & 0.948 & 0.964 & 0.989 & 0.965 & 0.935 & 0.911 & 0.964 & 0.960 & 0.942 & 0.958 & 0.929 & 0.936 \\
\hline \multirow[t]{5}{*}{ Modified Gompertz } & $\mathrm{R}_{\text {Max }}$ & 0.26 & 0.21 & 0.03 & 0.03 & 0.2 & 0.5 & 0.2 & 0.2 & 4.4 & 3.7 & 6.1 & 13.2 \\
\hline & $\mathrm{P}$ & 1.7 & 1.9 & 1.0 & 0.3 & 1.3 & 1.9 & 0.9 & 1.2 & 229.2 & 176.4 & 201.3 & 271.0 \\
\hline & $\lambda$ & 2.7 & 2.0 & 0.0 & 0.4 & 2.5 & 2.4 & 1.1 & 1.2 & 27.3 & 20.2 & 21.8 & 12.2 \\
\hline & RSS & 0.012 & 0.143 & 0.025 & 0.004 & 0.003 & 0.008 & 0.005 & 0.002 & 441.2 & 378.2 & 1179.5 & 1179.5 \\
\hline & $\mathrm{R}^{2}$ & 0.998 & 0.98 & 0.971 & 0.976 & 0.999 & 0.999 & 0.997 & 0.999 & 0.998 & 0.998 & 0.998 & 0.998 \\
\hline \multirow[t]{5}{*}{ Logistic } & $\mathrm{R}_{\text {Max }}$ & 0.26 & 0.24 & 0.03 & 0.04 & 0.2 & 0.5 & 0.2 & 0.2 & 4.8 & 3.9 & 6.1 & 12.9 \\
\hline & $\mathrm{P}$ & 1.6 & 1.89 & 0.92 & 0.30 & 1.3 & 1.9 & 0.9 & 1.1 & 206.2 & 165.6 & 195.4 & 268.4 \\
\hline & $\lambda$ & 3.0 & 2.7 & 0.1 & 0.8 & 3.0 & 2.6 & 1.3 & 1.4 & 29.9 & 22.1 & 22.7 & 12.6 \\
\hline & RSS & 0.003 & 0.162 & 0.031 & 0.003 & 0.002 & 0.003 & 0.013 & 0.008 & 59.3 & 370.9 & 794.8 & 794.8 \\
\hline & $\mathrm{R}^{2}$ & 0.999 & 0.978 & 0.964 & 0.980 & 0.999 & 1.000 & 0.992 & 0.997 & 1.000 & 0.998 & 0.998 & 0.998 \\
\hline \multirow[t]{5}{*}{ Transference } & $\mathrm{R}_{\text {Max }}$ & 0.29 & 0.25 & 0.04 & 0.05 & 0.2 & 0.5 & 0.3 & 0.3 & 2.4 & 2.4 & 3.6 & 11.4 \\
\hline & $\mathrm{P}$ & 1.7 & 2.2 & 1.5 & 0.3 & 1.4 & 2.0 & 1.0 & 1.2 & 2044.5 & 2044.5 & 518.3 & 304.2 \\
\hline & $\lambda$ & 1.37 & 1.19 & 0.0 & 0.46 & 1.6 & 1.5 & 1.1 & 1.1 & 7.4 & 7.4 & 7.4 & 4.3 \\
\hline & RSS & 0.176 & 0.195 & 0.014 & 0.005 & 0.111 & 0.343 & 0.010 & 0.026 & 17101.9 & 5869.6 & 22867.2 & 22867.2 \\
\hline & $\mathrm{R}^{2}$ & 0.969 & 0.973 & 0.983 & 0.967 & 0.966 & 0.955 & 0.994 & 0.989 & 0.943 & 0.960 & 0.947 & 0.947 \\
\hline
\end{tabular}



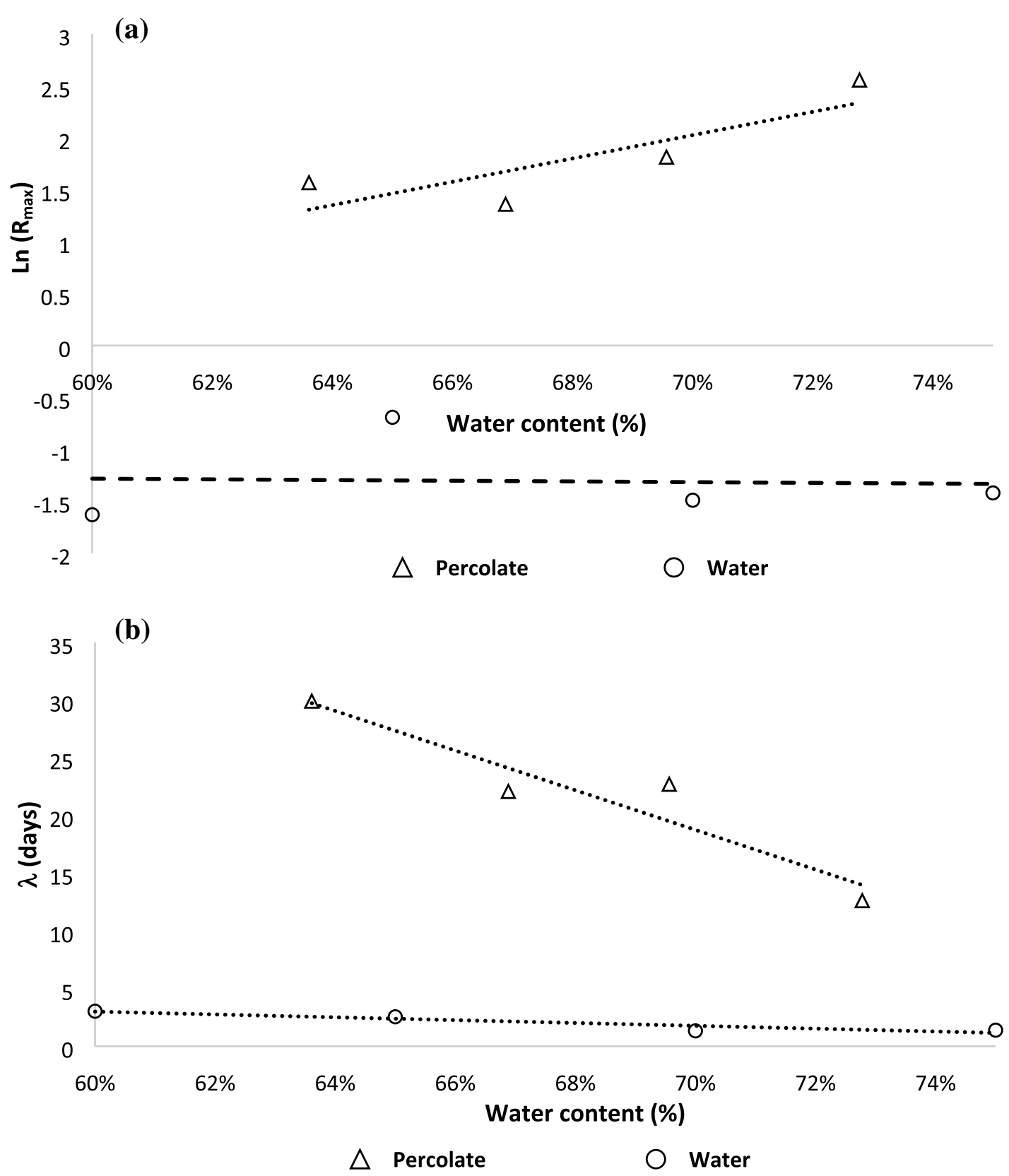

Fig. 3 Evolution of a lag phase and $\mathbf{b}$ logarithm of the maximum methane rate (Rmax) with water content when water and percolate were added to dry batch anaerobic digesters

models with a lag phase. The ratios of 1:2 and 1:16 had better fit, with an R-square of 0.999 and 0.980 , to the LM and $1: 4$ to the GM with 0.980 . Only the $1: 8$ ratio obtained a better fit with the $2 \mathrm{~S}$ model with an R-squared of 0.989 , one of the models without lag phase, as the production of methane was steady from the beginning of the batch digestion without an apparent delay (Figure S.1). When the effect of water addition on inhibition was tested all the best fitting models were those considering a lag phase, as there was a delay in the production of methane at the beginning of the digestion (Figure S.1). For trials at 40 and 35\% TS both the LM and GM provided an adequate fit with R-squared of 0.999 or 1.000 and slightly lower RSS in the case of the logistic model (Table 3). Trials at 30 and $25 \%$ were better fitted to the GM with R-squared of 0.997 and 0.999 . The trials with percolate addition were adequately fitted to the GM and LM models (Table 3), with R-squared values of 1.000 and 0.998 , but the RSS was always lower for the LM.

LM was chosen as the model for comparison between reactors, as it better captured the delay in methane formation 
observed in most reactors. The modelling data has been summarised in Fig. 3a and b. Some clear trends in the duration of transient inhibition were observed, with lag phases gradually shortening from 2 to 0.8 days as the amount of inoculum was reduced from a $1: 2$ ratio to $1: 16$. This is contrary to Elbeshbishy et al. [57], who suggested that the inoculum from digesters treating municipal solid waste contains high amounts of lignocellulosic fibres, hard to digest anaerobically. It is likely that a higher amount of fresh material, containing easily degradable organic matter, accelerated the fermentation process, shortening the lag phase but also resulting in a quicker acidification of the reactors, leading to the lowest methane production of $0.3 \pm 0.1 \mathrm{~L} \mathrm{CH}_{4} / \mathrm{kg} \mathrm{VS}_{\text {added }}$ for the lowest I:S compared to $1.2 \pm 1.0 \mathrm{~L} \mathrm{CH}_{4} / \mathrm{kg} \mathrm{VS}$ added for the highest ratio.

Percolate had a higher positive impact both on $\mathrm{R}_{\max }$ and methane yields than water addition (Table 3 ). Agreeing with Pommier et al. [16], when percolate was added the logarithm of $\mathrm{R}_{\max }$ showed a linear response with the percentage of water content in the ADs (Fig. 3a), showing an increase as a consequence of the higher free water availability. In contrast, water addition did not follow the trend (Fig. 3a), as the lack of buffering could not avoid acidification within the tested ranges, inhibiting the methanogenic archaea.

Both percolate and water addition strategies shortened lag phase as TS content was reduced (Table 3, Fig. 3b). A reduction in lag phase from 3 to 1.2 days at 40 and $25 \%$ TS was recorded when adding water, and from 29.9 to 12.6 days at 36 and $27 \%$ TS for percolate dosed reactors. Faster process kinetics with greater presence of free water were expected, as water allows bacteria transport, colonization of the particle reactive surface and solute diffusion through the porous medium [16], ultimately increasing the microbial hydrolysis rate that shortens the lag phase [15]. This being true, percolate addition resulted in longer lag phases compared to water (Table 3), which suggest transient inhibition of methanogenic archaea due to the composition of the percolate; which was overcome during the batch digestion, resulting in greater ultimate yields. This initial inhibition could potentially be aggravated if percolate is periodically recirculated in the ADs, ratifying the importance of understanding the evolution of percolate composition during the digestion time in order to balance recirculation of positively impacting composition (e.g. methanogens and alkalinity) against inhibitors accumulated in the liquid phase (e.g. VFA and FA).

\section{Conclusion}

This study focuses on the impact that changing I:S ratio and TS content (by addition of water and percolate) has on preventing inhibition of OFMSW dry anaerobic digestion, where literature is scarce. Variation of I:S alone did not suffice to prevent inhibition, and acidification of the ADs was observed due to the insufficient microbial communities to maintain the balance between hydrolysis and methanogenesis. Water addition resulted in shorter lag phases, as it promoted contact between microorganisms and substrate, although this better diffusion did not avoid acidification by accumulation of VFAs. Percolate addition was the only strategy within those tested that prevented reactor acidification, positively impacting methane yields but increasing lag phase compared to water addition. There is a need to understand evolution of percolate composition during batch dry $\mathrm{AD}$, to balance recirculation of nutrients, microbial communities and toxic compounds. This will help design percolate recirculation strategies (i.e. frequency and volumes) for optimised full-scale asset operations, with the perspective of allowing higher substrate throughout when using percolate recirculation, as it allows control of inhibitors at lower I:S.

Supplementary Information The online version contains supplementary material available at https://doi.org/10.1007/s12649-021-01503-0.

Acknowledgements This work was undertaken during I.R's Engineering Doctorate research at Cranfield University, funded jointly by the Engineering \& Physical Sciences Research Council (EPSRC) Skills Technology Research and Management (STREAM) EngD Programme (Grant EP/L015412/1) and Amey Waste Treatment.

Funding This work was undertaken during I.R's Engineering Doctorate research at Cranfield University, funded jointly by the Engineering \& Physical Sciences Research Council (EPSRC) Skills Technology Research and Management (STREAM) EngD Programme (Grant EP/ L015412/1) and Amey Waste Treatment.

Data Availability All relevant data are provided within the manuscript or as supplementary material.

\section{Declarations}

Conflicts of interest The authors have no relevant financial or nonfinancial interests to disclose.

Consent for Publication All co-authors have agreed to publication of this manuscript.

Open Access This article is licensed under a Creative Commons Attribution 4.0 International License, which permits use, sharing, adaptation, distribution and reproduction in any medium or format, as long as you give appropriate credit to the original author(s) and the source, provide a link to the Creative Commons licence, and indicate if changes were made. The images or other third party material in this article are included in the article's Creative Commons licence, unless indicated otherwise in a credit line to the material. If material is not included in the article's Creative Commons licence and your intended use is not permitted by statutory regulation or exceeds the permitted use, you will need to obtain permission directly from the copyright holder. To view a copy of this licence, visit http://creativecommons.org/licenses/by/4.0/. 


\section{References}

1. Li, Y., Park, S.Y., Zhu, J.: Solid-state anaerobic digestion for methane production from organic waste. Renew. Sustain. Energy Rev. 15, 821-826 (2011). https://doi.org/10.1016/j.rser.2010.07. 042

2. Eurostat: Municipal waste statistics (2018). https://ec.europa.eu/ eurostat/statistics-explained/index.php/Municipal_waste_stati stics\#Municipal_waste_generation. Accessed 2019

3. Kaza, S., Yao, L., Bhada-Tata, P., Van Woerden, F.: What a waste 2.0: a global snapshot of solid waste management to 2050. World Bank, Washington (2018)

4. Papageorgiou, A., Barton, J.R., Karagiannidis, A.: Assessment of the greenhouse effect impact of technologies used for energy recovery from municipal waste: a case for England. J. Environ. Manage. (2009). https://doi.org/10.1016/j.jenvman.2009.04.012

5. European commission: Review of waste policy and legislation (2019). http://ec.europa.eu/environment/waste/target_review.htm. Accessed 2019

6. Karthikeyan, O.P., Visvanathan, C.: Bio-energy recovery from high-solid organic substrates by dry anaerobic bio-conversion processes: a review. Rev. Environ. Sci. Biotechnol. 12, 257-284 (2013). https://doi.org/10.1007/s11157-012-9304-9

7. Rocamora, I., Wagland, S.T., Villa, R., Simpson, E.W., Fernández, O., Bajón-Fernández, Y.: Dry anaerobic digestion of organic waste: a review of operational parameters and their impact on process performance. Bioresour. Technol. (2020). https://doi.org/ 10.1016/j.biortech.2019.122681

8. Andre, L., Pauss, A., Ribeiro, T.: Solid anaerobic digestion: current trends and scientific hurdles. Bioresour. Technol. 1(247), 1027-37 (2018)

9. Chen, Y., Cheng, J.J., Creamer, K.S.: Inhibition of anaerobic digestion process: a review. Bioresour. Technol. 99, 4044-4064 (2008). https://doi.org/10.1016/j.biortech.2007.01.057

10. Di Maria, F., Barratta, M., Bianconi, F., Placidi, P., Passeri, D.: Solid anaerobic digestion batch with liquid digestate recirculation and wet anaerobic digestion of organic waste: comparison of system performances and identification of microbial guilds. Waste Manag. 59, 172-180 (2017). https://doi.org/10.1016/j.wasman.2016.10.039

11. Zhou, H., Wen, Z.: Solid-state anaerobic digestion for waste management and biogas production, pp. 147-168. Springer International Publishing, Cham (2019)

12. García-Bernet, D., Buffière, P., Latrille, E., Steyer, J.P., Escudié, R.: Water distribution in biowastes and digestates of dry anaerobic digestion technology. Chem. Eng. J. 172, 924-928 (2011). https:// doi.org/10.1016/j.cej.2011.07.003

13. Bollon, J., Benbelkacem, H., Gourdon, R., Buffière, P.: Measurement of diffusion coefficients in dry anaerobic digestion media. Chem. Eng. Sci. 89, 115-119 (2013). https://doi.org/10.1016/j. ces.2012.11.036

14. Ge, X., Xu, F., Li, Y.: Solid-state anaerobic digestion of lignocellulosic biomass: Recent progress and perspectives. Bioresour. Technol. 205, 239-249 (2016). https://doi.org/10.1016/j.biortech. 2016.01.050

15. Abbassi-Guendouz, A., Brockmann, D., Trably, E., Dumas, C., Delgenès, J.P., Steyer, J.P., Escudié, R.: Total solids content drives high solid anaerobic digestion via mass transfer limitation. Bioresour. Technol. 111, 55-61 (2012). https://doi.org/10.1016/j.biort ech.2012.01.174

16. Pommier, S., Chenu, D., Quintard, M., Lefebvre, X.: A logistic model for the prediction of the influence of water on the solid waste methanization in landfills. Biotechnol. Bioeng. (2007). https://doi.org/10.1002/bit.21241
17. Aran, C., Lefebvre, X., Houi, D.: Modelisation of mass and heattransfers in sanitary landfills. In: II Int. Symp. Anaerobic digestion solid waste, pp. 252-257. Barcelona (1999)

18. Qian, M., Zhang, Y., Li, R., Nelles, M., Stinner, W., Li, Y.: Effects of percolate recirculation on dry anaerobic co-digestion of organic fraction of municipal solid waste and corn straw. Energy Fuels 31, 12183-12191 (2017). https://doi.org/10.1021/acs.energyfuels. $7 \mathrm{~b} 01869$

19. Martin, D.J.: The site of reaction in solid-state digestion: a new hypothesis. Process Saf. Environ. Prot. 79, 29-37 (2001). https:// doi.org/10.1205/095758201531112

20. Staley, B.F., de los Reyes FL, Barlaz MA, : Effect of spatial differences in microbial activity, $\mathrm{pH}$, and substrate levels on methanogenesis initiation in refuse. Appl. Environ. Microbiol. 77, 2381-2391 (2011). https://doi.org/10.1128/AEM.02349-10

21. Forster-Carneiro, T., Pérez, M., Romero, L.I.: Influence of total solid and inoculum contents on performance of anaerobic reactors treating food waste. Bioresour. Technol. 99, 6994-7002 (2008). https://doi.org/10.1016/j.biortech.2008.01.018

22. Le Hyaric, R., Benbelkacem, H., Bollon, J., Bayard, R., Escudié, R., Buffière, P.: Influence of moisture content on the specific methanogenic activity of dry mesophilic municipal solid waste digestate. J. Chem. Technol. Biotechnol. 87, 1032-1035 (2012). https://doi.org/10.1002/jctb.2722

23. Raposo, F., De La Rubia, M.A., Fernández-Cegrí, V., Borja, R.: Anaerobic digestion of solid organic substrates in batch mode: an overview relating to methane yields and experimental procedures. Renew. Sustain. Energy Rev. 16, 861-877 (2012). https://doi.org/ 10.1016/j.rser.2011.09.008

24. Di Maria, F., Sordi, A., Micale, C.: Optimization of solid state anaerobic digestion by inoculum recirculation: the case of an existing mechanical biological treatment plant. Appl. Energy. 97, 462-469 (2012). https://doi.org/10.1016/j.apenergy.2011.12.093

25. Liu, G., Zhang, R., El-Mashad, H.M., Dong, R.: Effect of feed to inoculum ratios on biogas yields of food and green wastes. Bioresour. Technol. 100, 5103-5108 (2009). https://doi.org/10. 1016/j.biortech.2009.03.081

26. Hernández-Shek, M.A., André, L., Peultier, P., Pauss, A., Ribeiro, T.: Immersion effect on the anaerobic degradation and the rheological properties of straw-cattle manure (SCM) at $440 \mathrm{~L}$ batch pilot scale reactor. Waste Biomass Valoriz. (2021). https://doi.org/ 10.1007/s12649-021-01458-2

27. Meng, L., Maruo, K., Xie, L., Riya, S., Terada, A., Hosomi, M.: Comparison of leachate percolation and immersion using different inoculation strategies in thermophilic solid-state anaerobic digestion of pig urine and rice straw. Bioresour. Technol. 277, 216-220 (2019). https://doi.org/10.1016/j.biortech.2019.01.011

28. André, L., Ndiaye, M., Pernier, M., Lespinard, O., Pauss, A., Lamy, E., Ribeiro, T.: Methane production improvement by modulation of solid phase immersion in dry batch anaerobic digestion process: dynamic of methanogen populations. Bioresour. Technol. 207, 353-360 (2016). https://doi.org/10.1016/j.biortech.2016.02. 033

29. Vandevivere, P., De Baere, L., Verstraete, W.: Types of anaerobic digester for solid wastes, pp. 114-140. Iwa Publishing, London (2003)

30. Liao, X., Zhu, S., Zhong, D., Zhu, J., Liao, L.: Anaerobic codigestion of food waste and landfill leachate in single-phase batch reactors. Waste Manag. 34, 2278-2284 (2014). https://doi.org/10. 1016/j.wasman.2014.06.014

31. Wilson, L.P., Sharvelle, S.E., De Long, S.K.: Enhanced anaerobic digestion performance via combined solids- and leachate-based hydrolysis reactor inoculation. Bioresour. Technol. 220, 94-103 (2016). https://doi.org/10.1016/j.biortech.2016.08.024

32. Sponza, D.T., Ağdağ, O.N.: Impact of leachate recirculation and recirculation volume on stabilization of municipal solid wastes in 
simulated anaerobic bioreactors. Process Biochem. 39, 2157-2165 (2004). https://doi.org/10.1016/j.procbio.2003.11.012

33. Koch, K., Hafner, S.D., Weinrich, S., Astals, S.: Identification of critical problems in biochemical methane potential (BMP) tests from methane production curves. Front. Environ. Sci. (2019). https://doi.org/10.3389/fenvs.2019.00178

34. APHA: Standard methods for examination of water and wastewater. American Public Health Association, Washington (1999)

35. Ripley, L.E., Boyle, W.C., Converse, J.C.: Improved alkalimetric monitoring for anaerobic digestion of high-strenght wastes. Water Pollut. Control Fed. (1986). https://doi.org/10.1016/S02621762(99)80122-9

36. Hansen, K.H., Angelidaki, I., Ahring, B.K.: Anaerobic digestion of swine manure: inhibition by ammonia. Water Res. 32, 5-12 (1998). https://doi.org/10.1016/S0043-1354(97)00201-7

37. Bajón Fernández, Y., Green, K., Schuler, K., Soares, A., Vale, P., Alibardi, L., Cartmell, E.: Biological carbon dioxide utilisation in food waste anaerobic digesters. Water Res. (2015). https://doi. org/10.1016/j.watres.2015.06.011

38. Donoso-Bravo, A., Pérez-Elvira, S.I., Fdz-Polanco, F.: Application of simplified models for anaerobic biodegradability tests. Evaluation of pre-treatment processes. Chem. Eng. J. 160, 607614 (2010). https://doi.org/10.1016/j.cej.2010.03.082

39. Pellera, F.M., Gidarakos, E.: Effect of substrate to inoculum ratio and inoculum type on the biochemical methane potential of solid agroindustrial waste. J. Environ. Chem. Eng. 4, 3217-3229 (2016). https://doi.org/10.1016/j.jece.2016.05.026

40. Bhattarai, S., Oh, J.H., Euh, S.H., Krishna Kafle, G., Hyun Kim, D.: Simulation and model validation of sheet and tube type photovoltaic thermal solar system and conventional solar collecting system in transient states. Sol. Energy Mater. Sol. Cells. 103, 184-193 (2012). https://doi.org/10.1016/j.solmat.2012.04.017

41. Neves, L., Oliveira, R., Alves, M.M.: Influence of inoculum activity on the bio-methanization of a kitchen waste under different waste/inoculum ratios. Process Biochem. 39, 2019-2024 (2004). https://doi.org/10.1016/j.procbio.2003.10.002

42. Nallathambi Gunaseelan, V.: Effect of inoculum/substrate ratio and pretreatments on methane yield from Parthenium. Biomass Bioenergy 8, 39-44 (1995). https://doi.org/10.1016/09619534(94)00086-9

43. Forster-Carneiro, T., Fernández, L.A., Pérez, M., Romero, L.I., Álvarez, C.J.: Optimization of sebac start up phase of municipal solid waste anaerobic digestion. Chem. Biochem. Eng. Q 18, 429-439 (2004)

44. Guendouz, J., Buffière, P., Cacho, J., Carrère, M., Delgenes, J.P.: Dry anaerobic digestion in batch mode: Design and operation of a laboratory-scale, completely mixed reactor. Waste Manag. 30, 1768-1771 (2010). https://doi.org/10.1016/j.wasman.2009.12.024

45. Fernández, J., Pérez, M., Romero, L.I.: Effect of substrate concentration on dry mesophilic anaerobic digestion of organic fraction of municipal solid waste (OFMSW). Bioresour. Technol. 99, 6075-6080 (2008). https://doi.org/10.1016/j.biortech.2007.12.048

46. Kusch, S., Oechsner, H., Jungbluth, T.: Biogas production with horse dung in solid-phase digestion systems. Bioresour. Technol.
99, 1280-1292 (2008). https://doi.org/10.1016/j.biortech.2007.02. 008

47. Kusch, S., Oechsner, H., Jungbluth, T.: Effect of various leachate recirculation strategies on batch anaerobic digestion of solid substrates. Int. J. Environ. Waste Manag. 9, 69 (2012). https://doi.org/ 10.1504/IJEWM.2012.044161

48. Duan, N., Dong, B., Wu, B., Dai, X.: High-solid anaerobic digestion of sewage sludge under mesophilic conditions: feasibility study. Bioresour. Technol. (2012). https://doi.org/10.1016/j.biort ech.2011.10.090

49. Gallert, C., Winter, J.: Mesophilic and thermophilic anaerobic digestion of source-sorted organic waste: effect of ammonia on glucose degradation and methane production. Appl. Microbiol. Biotechnol. 48, 405-410 (1997)

50. Yabu, H., Sakai, C., Fujiwara, T., Nishio, N., Nakashimada, Y.: Thermophilic two-stage dry anaerobic digestion of model garbage with ammonia stripping. J. Biosci. Bioeng. 111, 312-319 (2011). https://doi.org/10.1016/j.jbiosc.2010.10.011

51. Fagbohungbe, M.O., Dodd, I.C., Herbert, B.M.J., Li, H., Ricketts, L., Semple, K.T.: High solid anaerobic digestion: operational challenges and possibilities. Environ. Technol. Innov. 4, 268-284 (2015). https://doi.org/10.1016/j.eti.2015.09.003

52. Benbelkacem, H., Bayard, R., Abdelhay, A., Zhang, Y., Gourdon, R.: Effect of leachate injection modes on municipal solid waste degradation in anaerobic bioreactor. Bioresour. Technol. 101, 5206-5212 (2010). https://doi.org/10.1016/j.biortech.2010.02.049

53. Dearman, B., Bentham, R.H.: Anaerobic digestion of food waste: comparing leachate exchange rates in sequential batch systems digesting food waste and biosolids. Waste Manag. 27, 1792-1799 (2007). https://doi.org/10.1016/j.wasman.2006.08.006

54. Güelfo, L.A.F., Alvarez-Gallego, C., Márquez, D.S., García, L.I.R.: Start-up of thermophilic-dry anaerobic digestion of OFMSW using adapted modified SEBAC inoculum. Bioresour. Technol. 101, 9031-9039 (2010). https://doi.org/10.1016/j.biort ech.2010.07.021

55. André, L., Durante, M., Pauss, A., Lespinard, O., Ribeiro, T., Lamy, E.: Quantifying physical structure changes and non-uniform water flow in cattle manure during dry anaerobic digestion process at lab scale: implication for biogas production. Bioresour. Technol. 192, 660-669 (2015). https://doi.org/10.1016/j.biortech. 2015.06.022

56. Demirer, G.N., Chen, S.: Anaerobic biogasification of undiluted dairy manure in leaching bed reactors. Waste Manag. (2008). https://doi.org/10.1016/j.wasman.2006.11.005

57. Elbeshbishy, E., Nakhla, G., Hafez, H.: Biochemical methane potential (BMP) of food waste and primary sludge: influence of inoculum pre-incubation and inoculum source. Bioresour. Technol. 110, 18-25 (2012). https://doi.org/10.1016/j.biortech.2012. 01.025

Publisher's Note Springer Nature remains neutral with regard to jurisdictional claims in published maps and institutional affiliations. 


\section{Authors and Affiliations}

Ildefonso Rocamora ${ }^{1}$ - Stuart T. Wagland ${ }^{1} \cdot$ Raffaella Villa $^{1,2} \cdot$ Edmon W. Simpson $^{3}$. Oliver Fernández ${ }^{3}$. Yadira Bajón-Fernández ${ }^{1}$

$\triangle$ Yadira Bajón-Fernández y.bajonfernandez@cranfield.ac.uk

1 School of Water, Energy and Environment, Cranfield University, Bedford, UK
2 Present Address: School of Engineering and Sustainable Development, De Montfort University, Leicester, UK

3 Amey PLC., Oxford, UK 